\title{
Exposure to carbon disulphide and ischaemic heart disease in a viscose rayon factory
}

\author{
P M SWEETNAM, ${ }^{1}$ S W C TAYLOR, ${ }^{2}$ P C ELWOOD $^{1}$ \\ From the MRC Epidemiology Unit, ${ }^{1}$ Cardiff CF2 3AS, and Courtaulds plc, ${ }^{2}$ Derby, UK
}

\begin{abstract}
The cohort of viscose rayon workers previously described by Tiller et al has been recon: structed and followed up to the end of 1982. The pattern of mortality at ages 45 to 64 for the extended period 1950-82 is similar to that described by Tiller et al for 1950-64. The spinners, the workers most heavily exposed to carbon disulphide, have a significantly higher mortality from atf causes than the least exposed group. The excess mortality is largely accounted for by ischaemic hearitu disease (IHD) for which the spinners have an SMR of 172. When mortality is related to an exposure score in the same group, both all cause $(p<0.01)$ and IHD $(p<0.001)$ mortality increase witi increasing exposure level. When this analysis is repeated covering all ages these trends become much less strong and only that for IHD remains significant $(p<0.05)$. Over the age of 65 there is tendency for mortality to decline with increasing exposure. This is contrary to expectation under the usual hypothesis that carbon disulphide promotes atherosclerosis. Instead it suggests that carbof disulphide has some type of reversible, direct cardiotoxic or thrombotic effect. This is supported by the findings that there is a stong trend $(\mathrm{p}<0.01)$ for IHD mortality to increase with increasing exposure in the previous two years. Further, both IHD (p<0.001) and total $(\mathrm{p}<0.01)$ mortalit show highly significant trends with exposure among current workers but no such trends amon workers who have left the industry.
\end{abstract}

The hazards of exposure to high concentrations of carbon disulphide $\left(\mathrm{CS}_{2}\right)$ have been known since the nineteenth century when it was used in the vulcanisation of rubber. Carbon disulphide is a neurotoxic poison, exposure to concentrations of the order of $1000 \mathrm{ppm}$ can cause acute psychosis and exposure to around $5000 \mathrm{ppm}$ is rapidly fatal.

In this century the main industrial use of carbon disulphide has been in the viscose rayon industry. Cellulose produced from wood pulp is converted, after treatment with caustic soda, into cellulose xanthate by the addition of carbon disulphide. The cellulose xanathate is dissolved in dilute caustic soda giving a solution called viscose. At times viscose process workers are exposed to carbon disulphide. The viscose solution is pumped through a jet into a warm sulphuric acid bath where the original cellulose is precipitated as a continuous thread. This is cut into short lengths, washed, and dried. Men working in this spinning department may be exposed to both carbon disulphide and hydrogen sulphide.

In 1954 Vigliani described 100 cases of poisoning from carbon disulphide that occurred in five viscose

Accepted 8 July 1986 rayon plants in Piedmont during 1940 and 1941. Polyneuritis was seen in $88 \%$ of these cases. Under the wartime conditions these men were exposed to concentrations ranging from 60 to $500 \mathrm{ppm}$. After the war conditions in rayon plants improved an exposures were considerably reduced.

Vigliani describes how, on moving from Turin to Milan in 1942, he began to see cases with "a vasculan". diffused encephalopathy." From 1943 to 1953 he savo 43 such cases, 15 of whom were aged under 50 . Hहै advanced the hypothesis that "prolonged exposure to $\mathrm{CS}_{2}$ can lead to a favourable situation for producin 8 atherosclerosis." He also described vascular lesions in animals exposed to $\mathrm{CS}_{2}$. Later workers report athero? sclerosis in animals exposed to $\mathrm{CS}_{2}{ }^{2}$

In 1968 Tiller et al produced the first evidenc? relating the development of coronary heart disease to 0 exposure to carbon disulphide among viscose rayor workers. ${ }^{3}$ They began with a proportional mortalite study in an area containing three rayon plants and found that $42 \%$ of deaths among viscose and spin ning process workers were certified to coronary heart disease. The corresponding proportion among other non-process, rayon workers was $24 \%$, whereas fo non-rayon workers it was $17 \%$. They then conducted 
a cohort study among the men employed at the most modern of the three factories. The cohort was followed up from 1950 to 1964 . Among men employed in the rayon industry for more than 10 years, those exposed to carbon disulphide had death rates from rayon workers. The findings of Tiller et al have since been supported by Hernberg and co-workers. ${ }^{45}$ They found that coronary mortality over a ten year period was more than twice as high in a cohort of 343 viscose rayon workers exposed for at least five years to $\mathrm{CS}_{2}$ as it was in a cohort of 343 paper mill workers matched for age and district of birth.

The viscose rayon industry has greatly diminished in size in Europe in the face of competition from other yarns. It is, however, a source of employment in many developing countries. Levels of exposure to $\mathrm{CS}_{2}$ have undoubtedly declined since the 1940s and 1950s, although few objective data are available. In the United Kingdom the threshold limit value (TLV) was $20 \mathrm{ppm}$ in the 1960s and has since been reduced to $10 \mathrm{ppm}$. The cohort study of Tiller et al is still much the largest that has been reported. ${ }^{3}$ An extension of the period of follow up of that cohort should yield important additional information, particularly in relation to the lower exposures to $\mathrm{CS}_{2}$ in the 1970s. We report here a follow up of that cohort to the end of 1982.

\section{Subjects and methods}

The population studied by Tiller $e t$ al was defined as all men who were employed at one factory for at least one year between 1 January 1945 and 31 December $1949 .^{3}$ They followed up this cohort from 1 January 1950 to 31 December 1964. Therefore, to be a member of the defined population the man had to be still alive on 1 January 1950 . We reconstructed the cohort from records preserved by Tiller. Without his invaluable help the study would not have been possible because company records before 1960 were incomplete.

Records were found for 3098 men. Of these, 128 men had worked for less than one year between 1945 coronary heart disease more than twice that of other

and 1949 and a further 31 had died before 1950. Thus 2939 men were eligible for the study. These men were traced through company records and through the National Health Service Central Registry. A positive tracing as alive or dead at the end of 1982 could not be made for $91(3 \cdot 1 \%)$ men. Seventy of these were known to have emigrated. The analysis reported here is thus based on 2848 men. Tiller et al largely restricted their analyses to men with at least 10 years experience in the viscose rayon industry and we have done likewise. A total of 1664 men had 10 or more years experience in the industry. For these men the actual date of study entry is either 1 January 1950 or the date of achieving 10 years experience in the industry, whichever is the later.

For each man, the data collected included date of birth, date and cause of death, and the description and dates of every job that he had had in the viscose rayon factory. All causes of death were coded to the ICD classification by one experienced coder. The revision used was that in force at the time that the death occurred. Thus a death may have been coded to the 6th, 7th, 8th, or 9th revisions of the ICD.

We tried to follow Tiller et al in classifying men into one of six occupational groups, according to their worst exposure to $\mathrm{CS}_{2}$. Men of foreman grade and above were classified as "staff" and the remainder as "operatives." Operatives were classed as:

(a) process workers who had worked in the spinning department (highest exposure to $\mathrm{CS}_{2}$ )

(b) process workers who had worked in the viscose making department but not in spinning (low to moderate exposure to $\mathrm{CS}_{2}$ )

(c) non-process fitters (some exposed at times to high levels of $\mathrm{CS}_{2}$ while maintaining machinery)

(d) other non-process workers (little or no exposure to $\mathrm{CS}_{2}$ ).

Staff were simply divided into two groups as process workers (with some exposure to $\mathrm{CS}_{2}$ ) and nonprocess workers (with no exposure to $\mathrm{CS}_{2}$ ). Table 1 gives the distribution of men by occupation group and length of time in the industry.

An exposure score was also calculated for all operTable 1 Number of men by occupation group and period spent in the viscose rayon indusiry

\begin{tabular}{lccr} 
& \multicolumn{1}{c}{ Occupation group } & $<10$ years & Total \\
\cline { 2 - 4 } Operatives: & 343 & 661 & 1004 \\
Spinner & 204 & 257 & 461 \\
Viscose & 75 & 55 & 130 \\
$\quad$ Non-process fitter & 508 & 373 & 881 \\
$\quad$ Other non-process & 12 & 192 & 204 \\
Staff: & 42 & 126 & 168 \\
$\quad$ Process & 1184 & 1664 & 2848 \\
$\quad$ Non-process & 1184 & & \\
Total & & & \\
\hline
\end{tabular}


Table 2 Codes used for specific causes of death under different revisions of the ICD

\begin{tabular}{|c|c|c|c|}
\hline \multirow{2}{*}{$\begin{array}{l}\text { Specific cause } \\
\text { of death }\end{array}$} & \multicolumn{3}{|c|}{ Codes used with ICD revision } \\
\hline & 6 th and 7 th & $8 t h$ & $9 t h$ \\
\hline $\begin{array}{l}\text { Ischaemic heart } \\
\text { disease } \\
\text { Other circulatory } \\
\text { disease }\end{array}$ & $\begin{array}{l}420,422 \\
330-334 \\
400-468 \\
\text { excluding } \\
420,422\end{array}$ & $\begin{array}{l}410-414 \\
390-458 \\
\text { excluding } \\
410-414\end{array}$ & $\begin{array}{l}410-414 \\
390-459 \\
\text { excluding } \\
410-414\end{array}$ \\
\hline
\end{tabular}

atives. Measurement of doses by means of personal monitors has been carried out only during the past six years. Before this, measurements of environmental levels of $\mathrm{CS}_{2}$ were done on an area basis. Taking into consideration personal monitoring results, previous area measurements, and the nature of the work, each job was allocated a $\mathrm{CS}_{2}$ rating. This task was performed by one of the authors (ST) together with an experienced senior member of staff who had been employed at the factory since 1946 . The $\mathrm{CS}_{2}$ ratings ranged from 0 (no exposure to $\mathrm{CS}_{2}$ ) to 4 (highest exposure to $\mathrm{CS}_{2}$ ). There is no doubt that those highest exposed on a continuous basis were the spinners who were allocated a rating of 4 . The next highest were the wash operatives (working within the spinning department) who were allocated a rating of 3 . A rating of 2 was allocated to most viscose operatives. They were exposed to intermittent high levels over a shift every third or fourth week since the majority of them rotated their job and spent much of their time in areas with no exposure to $\mathrm{CS}_{2}$. Likewise fitters, pipefitters, and their mates intermittently exposed to high $\mathrm{CS}_{2}$ levels were given a rating of 2 . All other operatives were given a rating of 1 (little exposure) or 0 (no exposure). The exposure score was then the product of this $\mathrm{CS}_{2}$ rating with the number of months spent in the particular job, summed over all jobs. This exposure score could be calculated over any chosen period. Exposure scores were not calculated for staff because of the difficulty of allocating a $\mathrm{CS}_{2}$ rating too many of the staff jobs.

The results are presented as standardised mortality ratios (SMRs). Man-years at risk were calculatef using $\mathrm{MYCL}^{6}$ in five year age groups within quin $\frac{5}{-}$ quennial calendar periods. Expected deaths werE obtained by applying the England and Wales death rates to the man-years at risk. The England and Wales rates used were the average annual age specifices rates for the appropriate quinquennial calendar $\overrightarrow{0}$ period. SMRs were calculated for total mortality, for ischaemic heart disease mortality, and for other circus. latory diseases. Table 2 shows the ICD codes used to define these specific causes under the different ICD revisions.

Significance tests were calculated using the usual assumption that the observed deaths follow the Poisson distribution whereas the expected deaths ares based on such large numbers that they may be takeno as without error. ${ }^{7}$

\section{Results}

There was some uncertainty over the accuracy of oupo reconstruction of the original cohort. The best means of dispelling this uncertainty was to repeat the analyo sis performed by Tiller et al and to compare ous results with their published figures. They restricted alo their analyses to the age range 45 to 64 years. $^{2}$ Of the 1664 men with more than 10 years experience in the industry, 1334 were aged between 45 and 64 at somet time between entry and the end of 1964 . Table 35 shows the comparison for man-years at risk and fore ischaemic heart disease (IHD) deaths. In general the two sets of results compare well. It seems that we haves classed as spinners some of the men that Tiller et at classed as viscose workers. This reflects the difficulty of job classification. The only discrepancy of any size. is in the observed deaths from IHD among the other non-process workers and this is partly explained bys

Table 3 Man-years and observed and expected deaths from IHD. The current reconstructed cohort compared with the original published results

\begin{tabular}{|c|c|c|c|c|c|c|}
\hline \multirow[b]{3}{*}{ Occupation group } & \multicolumn{3}{|c|}{ Tiller et al analysis } & \multicolumn{3}{|c|}{ Current analysis } \\
\hline & \multirow{2}{*}{$\begin{array}{l}\text { Man-years } \\
\text { at risk }\end{array}$} & \multicolumn{2}{|c|}{ IHD deaths } & \multirow{2}{*}{$\begin{array}{l}\text { Man-years } \\
\text { at risk }\end{array}$} & \multicolumn{2}{|c|}{ IHD deaths } \\
\hline & & Observed & Expected & & Observed & Expected \\
\hline \multirow{4}{*}{$\begin{array}{l}\text { Operatives: } \\
\text { Spinner } \\
\text { Viscose } \\
\text { Non-process fitter } \\
\text { Other non-process } \\
\text { Staff: } \\
\text { Process } \\
\text { Non-process }\end{array}$} & & & & & & \\
\hline & $\begin{array}{l}4585 \\
2221 \\
* \\
1997\end{array}$ & $\begin{array}{r}28 \\
5 \\
6 \\
6\end{array}$ & $\begin{array}{r}14.6 \\
7.2 \\
1.8 \\
8.0\end{array}$ & $\begin{array}{r}4924 \\
1815 \\
413 \\
2258\end{array}$ & $\begin{array}{r}28 \\
5 \\
6 \\
11\end{array}$ & $\begin{array}{r}16.9 \\
6.2 \\
1.8 \\
9.8\end{array}$ \\
\hline & & & & & & \\
\hline & $\begin{array}{r}1502 \\
752\end{array}$ & $\begin{array}{l}9 \\
3\end{array}$ & $\begin{array}{l}4 \cdot 3 \\
2 \cdot 3\end{array}$ & $\begin{array}{r}1482 \\
768\end{array}$ & $\begin{array}{l}9 \\
3\end{array}$ & $\begin{array}{l}4 \cdot 5 \\
2 \cdot 6\end{array}$ \\
\hline \multicolumn{7}{|c|}{$\begin{array}{l}\text { *Not given. } \\
\text { Follow up to } 31 \text { December 1964; ages } 45 \text { to } 64 \text {; men with } 10 \text { or more years experience in the industry. }\end{array}$} \\
\hline
\end{tabular}


Table 4 Observed and expected deaths and SMRs by cause and occupation group; ages 45 to 64. Period of follow up 1950-82

\begin{tabular}{|c|c|c|c|c|c|c|c|c|c|}
\hline \multirow[b]{2}{*}{ Occupation group } & \multicolumn{3}{|l|}{$I H D$} & \multicolumn{3}{|c|}{ Other circulatory } & \multicolumn{3}{|c|}{ All causes } \\
\hline & Obs & $\operatorname{Exp}$ & $S M R$ & Obs & $\operatorname{Exp}$ & $S M R$ & Obs & $\operatorname{Exp}$ & $S M R$ \\
\hline \multicolumn{10}{|l|}{ Operatives: } \\
\hline Spinner & $73^{* * *}$ & $42 \cdot 5$ & 172 & $33^{* *}$ & $20 \cdot 0$ & 165 & $183^{* * *}$ & $134 \cdot 6$ & 136 \\
\hline Viscose & 19 & $17 \cdot 1$ & 111 & 5 & $8 \cdot 0$ & 63 & 53 & 53.8 & 99 \\
\hline Non-process fitter & $9 * *$ & $3 \cdot 1$ & 290 & 0 & 1.6 & 0 & 13 & $10 \cdot 3$ & 126 \\
\hline Other non-process & 22 & $18 \cdot 4$ & 120 & 16 & $9 \cdot 5$ & 168 & 62 & $61 \cdot 1$ & 101 \\
\hline \multicolumn{10}{|l|}{ Staff: } \\
\hline Process & 20 & $13 \cdot 2$ & 152 & 5 & $6 \cdot 1$ & 82 & 44 & $41 \cdot 3$ & 107 \\
\hline Non-process & 10 & $7 \cdot 4$ & 135 & 4 & 3.4 & 118 & 20 & $23 \cdot 0$ & 87 \\
\hline
\end{tabular}

Observed deaths significantly greater than expected: ${ }^{*} p<0.05 ;{ }^{* *} p<0.01 ;{ }^{* * *} p<0.001$.

the difficulties in job classification. Of the 11 men that we classed as other non-process workers who died of IHD, one was classed by Tiller et al as a viscose process worker and two as spinners. Overall, we found seven more deaths among our cohort than did Tiller et al and of these, five were certified to ischaemic heart disease. The comparison is, however, sufficiently close to conclude that the original cohort has been successfully reconstructed.

Table 3 also shows the high mortality from ischaemic heart disease among the spinning operatives $(\mathrm{SMR}=166)$ and the process staff $(\mathrm{SMR}=$ 200) as reported by Tiller et al. When the period of follow up is extended to the end of 1982 this pattern is maintained (table 4). All cause mortality among spinning operatives is significantly $(p<0.001)$ higher than expected and the SMR of 136 is also significantly $(p<0.05)$ higher than the SMR of 101 found among the other non-process operatives, the least exposed group of operatives. The excess total deaths among the spinners are almost entirely accounted for by an excess of deaths from circulatory causes, most being due to IHD for which the SMR is $172(p<0.001)$. There is no evidence of any excess mortality among the viscose process workers. The overall pattern of mortality in the extended period of follow up from 1965 to 1982 is similar to that seen in the period 1950-64.

Classification by occupation group indicates the highest level of $\mathrm{CS}_{2}$ that a worker will have been exposed to but takes no account of the duration of that exposure. In table 5 mortality from all causes, from IHD, and from other circulatory causes is related to exposure score. Staff have been excluded because of the difficulty of allocating them an exposure score. As in tables 3 and 4 , the analysis is limited to men with at least 10 years experience in the industry and it is restricted to ages 45 to 64 . There is a significant $(p<0.01)$ trend for all cause mortality to increase with exposure, and a pronounced and highly significant $(p<0.001)$ trend for IHD mortality to increase with exposure. Mortality from other circulatory causes is generally high but shows no association with exposure. In this instance the exposure score has been calculated up to the point of study entry. This avoids the bias that is introduced when the periods over which exposure is measured and mortality is analysed are permitted to overlap. ${ }^{8}$ When exposure is calculated up to 1960 and mortality analysed from 1960 to 1982 a similar pattern emerges.

The main hypothesis put forward to explain the excess mortality from IHD is that $\mathrm{CS}_{2}$ promotes atherosclerosis. ${ }^{1-3}$ If this is so then we should expect IHD mortality to remain high after exposure to $\mathrm{CS}_{2}$ ceases. In particular, there is no reason to limit analysis to ages 45 to 64 . In table 6 mortality is again related to exposure score but the age restriction is removed. There are still trends for total and IHD mortality to increase with exposure but they are much less strong than those seen at ages 45 to 64 . For IHD mortality the trend is just significant at the $5 \%$ level whereas that for total mortality is not statistically

Table 5 Observed and expected deaths and SMRs by exposure score among operatives; ages 45 to 64. Period of follow up $1950-82$

\begin{tabular}{|c|c|c|c|c|c|c|c|c|c|}
\hline \multirow[b]{2}{*}{ Exposure score } & \multicolumn{3}{|l|}{$I H D$} & \multicolumn{3}{|c|}{ Other circulatory } & \multicolumn{3}{|c|}{ All causes } \\
\hline & Obs & $\operatorname{Exp}$ & $S M R$ & Obs & $\operatorname{Exp}$ & $S M R$ & Obs & Exp & $S M R$ \\
\hline $\begin{array}{c}0-99 \\
100-199 \\
200-299 \\
\geqslant 300\end{array}$ & $\begin{array}{r}4 \\
25 \\
47 \\
47\end{array}$ & $\begin{array}{r}8 \cdot 1 \\
26 \cdot 3 \\
25 \cdot 4 \\
21 \cdot 4\end{array}$ & $\begin{array}{r}49 \\
95 \\
185 \\
220\end{array}$ & $\begin{array}{r}6 \\
21 \\
9 \\
18\end{array}$ & $\begin{array}{r}4.0 \\
12.4 \\
11.9 \\
10.8\end{array}$ & $\begin{array}{r}150 \\
169 \\
76 \\
167\end{array}$ & $\begin{array}{r}20 \\
87 \\
106 \\
98\end{array}$ & $\begin{array}{l}26 \cdot 2 \\
82.9 \\
79.9 \\
70 \cdot 6\end{array}$ & $\begin{array}{r}76 \\
105 \\
133 \\
139\end{array}$ \\
\hline
\end{tabular}

Test for trend: all causes $\chi^{2}(1 \mathrm{df})=8.1 ; \mathrm{p}<0.01$. IHD $\chi^{2}(1 \mathrm{df})=18.4 ; \mathrm{p}<0.001$. 
significant. In fact, above age 65 there is no trend of total mortality with exposure, and IHD mortality tends to decline with increasing exposure. This finding suggests that any hazard may cease when exposure ceases and hence that the effect is some type of reversible, direct cardiotoxic or thrombotic effect.

The measure of exposure used in tables 5 and 6 is the exposure-months score calculated up to the point of study entry. This is not necessarily a good measure of current or recent exposure. To test better the hypothesis of a reversible direct effect, mortality was then related to the exposure-months score in the previous two years. Each man year from the anniversary of study entry was allocated to the appropriate five year age group and calendar period and to one of five exposure-months groups $(0,1-23,24-47,48-71$, and 72-96) according to the exposure in the immediately previous two years. Thus any one man might contribute man-years to all five exposure groups. Two years after having left his last $\mathrm{CS}_{2}$ exposed job a man's exposure score would be 0 and would remain so. Thus most of the experience after age 65 would have a zero exposure score.

Mortality in relation to exposure to $\mathrm{CS}_{2}$ in the previous two years is shown in table 7. Again the analysis is restricted to operatives with at least 10 years experience in the industry. There is no convincing evidence that all cause mortality varies with exposure in the last two years $\left(\chi^{2}(4 \mathrm{df})=7 \cdot 8, \mathrm{p}=0 \cdot 10, \mathrm{NS}\right)$ and the variations that do exist show no evidence of a consistent trend with exposure. There are highly significant $(p<0.01)$ differences in IHD mortality between the different exposure score groups and in particular there is a trend $(\mathrm{p}<0.01)$ for IHD mortality to increase with exposure in the last two years. The most pronounced increase occurs in workers with exposure scores greater than 48 . The only workers who could obtain such scores are spinners, wash operatives fitters and pipefitters and their mates, and viscose operatives. They are all at risk of having been exposef to high levels of $\mathrm{CS}_{2}$. As in other analyses (tables 4 and 5) mortality from other circulatory diseases shows an unusual pattern. In general it is high with SMRs of the order of 150 to 170 but there is one exposure score group in which it is very low. There $i \overrightarrow{8,}$ however, no suggestion of any trend with exposure $\frac{\text { O }}{\circ}$

In table 7 nearly two thirds of both observed an expected deaths occur in the group with no exposure to carbon disulphide in the previous two years. This group is a mixture of current workers with n $\hat{\jmath}$ exposure and workers who have left the industring maybe many years before. In table 8 mortality is related to interval since last employment and exposure score up to the time of study entry. The group described as current workers are those still i⿱ employment or who have left the factory within the past year. This latter group were included with the current workers to get over the problem of workers who leave the industry because they are ill.

Total mortality varies significantly $\left(\chi^{2}(2 \mathrm{df})\right.$ $12.3, \mathrm{p}<0.01)$ with interval since last employment. is lowest among the current workers and highest onf to nine years after leaving employment. Within thi current workers total mortality increases significant with exposure $\left(\chi^{2}(1 \mathrm{df})=8.8, p<0.01\right)$. There some suggestion of a similar trend one to nine years

Table 6 Observed and expected deaths and SMRs by exposure score among operatives; all ages. Period of follow up 1950-8

\begin{tabular}{|c|c|c|c|c|c|c|c|c|c|}
\hline \multirow[b]{2}{*}{ Exposure score } & \multicolumn{3}{|l|}{$I H D$} & \multicolumn{3}{|c|}{ Other circulatory } & \multicolumn{3}{|c|}{ All causes } \\
\hline & $O b s$ & $\operatorname{Exp}$ & $S M R$ & Obs & $\operatorname{Exp}$ & $S M R$ & Obs & $\operatorname{Exp}$ & $S M R$ \\
\hline $\begin{array}{l}0-99 \\
100-199 \\
200-299 \\
\geqslant 300\end{array}$ & $\begin{array}{l}28 \\
79 \\
80 \\
80\end{array}$ & $\begin{array}{l}28 \cdot 1 \\
68 \cdot 1 \\
58 \cdot 1 \\
55 \cdot 7\end{array}$ & $\begin{array}{l}100 \\
116 \\
138 \\
144\end{array}$ & $\begin{array}{l}28 \\
68 \\
48 \\
57\end{array}$ & $\begin{array}{l}20 \cdot 0 \\
42 \cdot 5 \\
34 \cdot 4 \\
35 \cdot 8\end{array}$ & $\begin{array}{l}140 \\
160 \\
140 \\
159\end{array}$ & $\begin{array}{r}94 \\
261 \\
236 \\
227\end{array}$ & $\begin{array}{r}95.5 \\
223.0 \\
188.4 \\
186.7\end{array}$ & $\begin{array}{r}98 \\
117 \\
125 \\
122\end{array}$ \\
\hline
\end{tabular}

Table 7 Observed and expected deaths and SMRs by exposure score in the last two years; all ages. Period of follow up 1950-82

\begin{tabular}{|c|c|c|c|c|c|c|c|c|c|}
\hline \multirow{2}{*}{$\begin{array}{l}\text { Exposure score } \\
\text { in previous } \\
2 \text { years }\end{array}$} & \multicolumn{3}{|l|}{$I H D$} & \multicolumn{3}{|c|}{ Other circulatory } & \multicolumn{3}{|c|}{ All causes } \\
\hline & Obs & $\operatorname{Exp}$ & $S M R$ & Obs & $\operatorname{Exp}$ & $S M R$ & Obs & $\operatorname{Exp}$ & $S M R$ \\
\hline $\begin{array}{l}0 \\
1-23 \\
24-47 \\
48-71 \\
72-96\end{array}$ & $\begin{array}{r}149 \\
12 \\
30 \\
49 \\
27\end{array}$ & $\begin{array}{r}129 \cdot 4 \\
11 \cdot 3 \\
28 \cdot 9 \\
29 \cdot 0 \\
11 \cdot 4\end{array}$ & $\begin{array}{l}115 \\
106 \\
104 \\
169 \\
236\end{array}$ & $\begin{array}{r}149 \\
10 \\
26 \\
7 \\
9\end{array}$ & $\begin{array}{r}89 \cdot 4 \\
6 \cdot 7 \\
15 \cdot 7 \\
15 \cdot 1 \\
5 \cdot 9\end{array}$ & $\begin{array}{r}167 \\
149 \\
166 \\
46 \\
153\end{array}$ & $\begin{array}{r}528 \\
44 \\
93 \\
99 \\
54\end{array}$ & $\begin{array}{r}429 \cdot 0 \\
36 \cdot 4 \\
95 \cdot 3 \\
95 \cdot 1 \\
37 \cdot 9\end{array}$ & $\begin{array}{r}123 \\
121 \\
98 \\
104 \\
142\end{array}$ \\
\hline
\end{tabular}

Test for trend: IHD $\chi^{2}(1 \mathrm{df})=10.5 ; \mathrm{p}<0.01$. 
Table 8 Observed and expected deaths and SMRs by interval since last employment and exposure score; all ages. Period of follow up 1950-82

\begin{tabular}{|c|c|c|c|c|c|c|c|c|c|c|}
\hline \multirow{2}{*}{$\begin{array}{l}\text { Interval } \\
\text { since last } \\
\text { employment }\end{array}$} & \multirow{2}{*}{$\begin{array}{l}\text { Exposure } \\
\text { score }\end{array}$} & \multicolumn{3}{|l|}{$I H D$} & \multicolumn{3}{|c|}{ Other circulatory } & \multicolumn{3}{|c|}{ All causes } \\
\hline & & Obs & $\operatorname{Exp}$ & $S M R$ & Obs & $\operatorname{Exp}$ & $S M R$ & Obs & $\operatorname{Exp}$ & $S M R$ \\
\hline \multirow[t]{2}{*}{$\begin{array}{l}\text { Current } \\
\text { workers }\end{array}$} & $\begin{array}{l}0-99 \\
100-199 \\
200-299 \\
\geqslant 300\end{array}$ & $\begin{array}{r}9 \\
21 \\
48 \\
45\end{array}$ & $\begin{array}{l}10 \cdot 0 \\
26 \cdot 9 \\
26 \cdot 6 \\
21 \cdot 4\end{array}$ & $\begin{array}{r}90 \\
78 \\
180 \\
210\end{array}$ & $\begin{array}{r}3 \\
19 \\
9 \\
15\end{array}$ & $\begin{array}{r}6 \cdot 0 \\
14 \cdot 3 \\
13 \cdot 7 \\
11 \cdot 7\end{array}$ & $\begin{array}{r}50 \\
133 \\
66 \\
128\end{array}$ & $\begin{array}{r}26 \\
74 \\
102 \\
89\end{array}$ & $\begin{array}{l}33 \cdot 9 \\
88 \cdot 4 \\
86 \cdot 4 \\
72 \cdot 4\end{array}$ & $\begin{array}{r}77 \\
84 \\
118 \\
123\end{array}$ \\
\hline & All & 123 & $84 \cdot 9$ & 145 & 46 & $45 \cdot 7$ & 101 & 291 & $281 \cdot 1$ & 104 \\
\hline \multirow[t]{2}{*}{$\begin{array}{l}1 \text { to } 9 \text { years } \\
\text { after leaving }\end{array}$} & $\begin{array}{l}0-99 \\
100-199 \\
200-299 \\
\geqslant 300\end{array}$ & $\begin{array}{l}12 \\
34 \\
20 \\
24\end{array}$ & $\begin{array}{l}10 \cdot 6 \\
26 \cdot 7 \\
20 \cdot 6 \\
19 \cdot 5\end{array}$ & $\begin{array}{r}113 \\
127 \\
97 \\
123\end{array}$ & $\begin{array}{l}12 \\
34 \\
27 \\
30\end{array}$ & $\begin{array}{r}7 \cdot 7 \\
17 \cdot 6 \\
13 \cdot 0 \\
12 \cdot 5\end{array}$ & $\begin{array}{l}156 \\
193 \\
208 \\
240\end{array}$ & $\begin{array}{r}37 \\
115 \\
94 \\
96\end{array}$ & $\begin{array}{l}35 \cdot 3 \\
86 \cdot 7 \\
65 \cdot 6 \\
63 \cdot 2\end{array}$ & $\begin{array}{l}105 \\
133 \\
143 \\
152\end{array}$ \\
\hline & All & 90 & $77 \cdot 4$ & 116 & 103 & $50 \cdot 8$ & 203 & 342 & $250 \cdot 8$ & 136 \\
\hline \multirow[t]{2}{*}{$\begin{array}{l}10 \text { or more } \\
\text { years after } \\
\text { leaving }\end{array}$} & $\begin{array}{c}0-99 \\
100-199 \\
200-299 \\
\geqslant 300\end{array}$ & $\begin{array}{r}7 \\
24 \\
12 \\
11\end{array}$ & $\begin{array}{r}7 \cdot 5 \\
14 \cdot 4 \\
10 \cdot 8 \\
14 \cdot 8\end{array}$ & $\begin{array}{r}93 \\
167 \\
111 \\
74\end{array}$ & $\begin{array}{l}13 \\
15 \\
12 \\
12\end{array}$ & $\begin{array}{r}6 \cdot 3 \\
10 \cdot 5 \\
7 \cdot 8 \\
11 \cdot 7\end{array}$ & $\begin{array}{l}206 \\
143 \\
154 \\
103\end{array}$ & $\begin{array}{l}31 \\
72 \\
40 \\
42\end{array}$ & $\begin{array}{l}26 \cdot 2 \\
48 \cdot 0 \\
36 \cdot 4 \\
51 \cdot 1\end{array}$ & $\begin{array}{r}118 \\
150 \\
110 \\
82\end{array}$ \\
\hline & All & 54 & $47 \cdot 5$ & 114 & 52 & $36 \cdot 3$ & 143 & 185 & $161 \cdot 7$ & 114 \\
\hline
\end{tabular}

Test for trend: All causes-current workers $\chi^{2}(1 \mathrm{df})=8.8, \mathrm{p}<0.01$.

$$
\begin{aligned}
& -1 \text { to } 9 \text { years after leaving } \chi^{2}(1 \mathrm{df}=3 \cdot 6 \text {, NS. } \\
& \text { IHD current workers } \chi^{2}(1 \mathrm{df}=15 \cdot 8, \mathrm{p}<0 \cdot 001 . \\
& \text { Other circulatory-1 to } 9 \text { years after leaving } \chi^{2}(1 \mathrm{df})=1 \cdot 7 \text {, NS. } \\
& \geqslant 10 \text { years after leaving } \chi^{2}(1 \mathrm{df})=2 \cdot 6 \text {, NS. }
\end{aligned}
$$

after leaving the factory but this does not reach the conventional $5 \%$ level of statistical significance. There is no such trend 10 or more years after leaving.

Mortality from IHD is highest (SMR = 145) among the current workers but the difference between the three employment groups is not significant. Within the current workers, however, there is a powerful trend $\left(\chi^{2}(1 \mathrm{df})=15.8, \mathrm{p}<0.001\right)$ for IHD mortality to increase with exposure. There is no such trend after operatives have left the factory. Conversely, mortality from other circulatory diseases is higher after leaving the factory $\left(\chi^{2}(2 \mathrm{df})=16.6\right.$, $\mathrm{p}<0.001)$. Mortality from other circulatory diseases increases with exposure in men one to nine years after leaving the factory, but there is a similar trend in the opposite direction 10 or more years after leaving the factory. Neither of these trends, however, even approaches the conventional $5 \%$ level of statistical significance.

\section{Discussion}

The original cohort of men followed up by Tiller $e a^{3}$ from 1950 to 1964 has been successfully reconstructed and the follow up extended to 1982. Among men who had worked for at least $\mathbf{1 0}$ years in the viscose rayon industry, Tiller et al found that between ages 45 and 64 mortality from ischaemic heart disease was high in those who had worked in the spinning departments. ${ }^{3}$ When this analysis is extended to 1982 the same group of men are found to have higher mortality than expected from all causes. The excess deaths are almost entirely accounted for by an excess of circulatory system deaths, the main component of which is an excess of deaths from IHD. The spinning operatives have a SMR for IHD of 172. There was no evidence of any excess mortality among the viscose process workers. In general, the pattern of mortality in the period $1965-82$ is similar to that seen in 1950-64.

Men in the spinning departments are exposed to much higher levels of carbon disulphide $\left(\mathrm{CS}_{2}\right)$ than men in the viscose making department. But, as several workers $^{39}$ have pointed out, some men in the spinning departments of viscose rayon factories are exposed to both $\mathrm{CS}_{2}$ and hydrogen sulphide $\left(\mathrm{H}_{2} \mathrm{~S}\right)$. The excess mortality in the spinning departments could be explained either by the higher levels of $\mathrm{CS}_{2}$ or by the exposure to $\mathrm{H}_{2} \mathrm{~S}$. Tiller et al concluded that $\mathrm{H}_{2} \mathrm{~S}$ was unlikely to be the causative agent. ${ }^{3}$ One reason for this was that in their proportional mortality study they found an excess of 13 observed against $4 \cdot 6$ expected deaths from IHD among the viscose workers in the two older factories. Viscose workers have no exposure to $\mathrm{H}_{2} \mathrm{~S}$ and in those two older factories had much higher exposures to $\mathrm{CS}_{2}$ than viscose workers in the modern factory on which the cohort study is based.

Within the spinning department are three sections: spinning, wash, and drying. In the spinning section men are exposed to the highest levels of $\mathrm{CS}_{2}$ and also to $\mathrm{H}_{2} \mathrm{~S}$. In the wash section they are exposed to levels of $\mathrm{CS}_{2}$ that are nearly as high as in the spinning 
section but to considerably lower levels of $\mathrm{H}_{2} \mathrm{~S}$. Men in the drying section are exposed to little $\mathrm{CS}_{2}$ and no $\mathrm{H}_{2} \mathrm{~S}$. A comparison of those men who had worked as spinners with those who had worked as washers but not as spinners should give some indication of the effect of exposure to $\mathrm{H}_{2} \mathrm{~S}$. Unfortunately, the number of men whom we were sure had been pure washers was small, only 66 . Between the ages of 45 and 64 there were, among the washers, seven observed deaths from ischaemic heart disease as opposed to 3.7 expected $(S M R=188)$. Among the men who had worked in the spinning section there were 29 observed deaths against 15.6 expected $(S M R=186)$. These numbers are small but they give no support to the thesis that $\mathrm{H}_{2} \mathrm{~S}$ is the causative agent.

The trends that we have shown for ischaemic heart disease mortality to increase with increasing exposure to $\mathrm{CS}_{2}$ also point to $\mathrm{CS}_{2}$ as the causative agent. It has to be admitted that the exposure score is crude. We rated each job on a scale from 0 to 4 . We then summed the product of that rating with the months spent in the job for each job that the man had done in the period under consideration. This assumes that the exposure rating score is on an interval scale, which it is not. Nevertheless, we would argue that it is a better index of exposure to $\mathrm{CS}_{2}$ than the occupational group. The classification into occupational group makes no allowance for the period spent in the job and it combines together jobs which may have widely differing exposures to $\mathrm{CS}_{2}$. For example, the group of spinning operatives comprises spinners, washers, and dryers whose different exposures to $\mathrm{CS}_{2}$ and $\mathrm{H}_{2} \mathrm{~S}$ have already been described. It is also true that many of the men with the highest exposure scores are the men who are additionally exposed to $\mathrm{H}_{2} \mathrm{~S}$. We thus cannot rule out the possibility that $\mathrm{H}_{2} \mathrm{~S}$ is involved. On balance, however, it seems to us more likely that $\mathrm{CS}_{2}$ is the causative agent.

The main hypothesis previously put forward to explain the association between exposure to carbon disulphide and ischaemic heart disease is that exposure to carbon disulphide promotes atherosclerosis. ${ }^{1-3}$ Occupational group is a measure of the worst ever exposure to carbon disulphide but takes no account of the duration of that exposure. If $\mathrm{CS}_{2}$ promotes atherosclerosis then it may well be that total exposure to $\mathrm{CS}_{2}$ is more important than worst exposure. An exposure score was derived for each man. Between ages 45 and 64 both total mortality and IHD mortality rose with increasing exposure score, the latter considerably.

If $\mathrm{CS}_{\mathbf{2}}$ promotes atherosclerosis, however, then we would expect mortality from IHD, and perhaps from other circulatory diseases, to remain high even when exposure has ceased. In particular there is no reason to exclude experience over the age of 65 . When the analyses are repeated using all ages, the trends for total and IHD mortality to increase with exposure are. much decreased. This happens because at age 65 anc above there is no increase in mortality with increasing? exposure which suggests that the effect of $\mathrm{CS}_{2}$ is reversible and that the risk disappears after exposure ceases. The fact that mortality from other circulatory causes, while generally high, shows no sign of anye increase with exposure also argues against thes hypothesis that $\mathrm{CS}_{2}$ promotes atherosclerosis.

If the effect is a reversible, direct effect then mor: tality should be more strongly related to recentw exposure than to total exposure, and there is soms evidence (table 7) that this is so. IHD mortality shows a strong trend to increase with exposure to $\mathrm{CS}_{2}$ in the immediately previous two years. Further evidence toof support the hypothesis of a reversible effect is found in the fact that mortality from IHD is higher among current workers $(\mathrm{SMR}=145)$ than among those who had left who had an SMR of 116 one to nine years after leaving and of 114 , ten or more years after $\vec{b}$ Among the current workers there is a pronounced? increase in death from IHD with previous exposure the SMR rising from 90 in the lowest exposed group to 210 in the highest. There were no such trends after leaving the factory. Mortality from other circulatory causes was much higher after leaving the factory bus there was no evidence that this was related to pase exposure.

All these results are based on the 1664 men whoD had spent at least 10 years in the viscose rayon indus try. This is why the results reported here show no? evidence of a healthy worker effect. ${ }^{10}$ The major com 3 ponent of the healthy worker effect is the initial selec tion of a healthy population for employment. This will have largely disappeared after 10 years. It couldo be argued that if the effect of $\mathrm{CS}_{2}$ is direct then ip might also be seen in the 1184 men with less than 10 years experience in the industry. In fact there is no suggestion that mortality from ischaemic heart dis ease is related to occupation group among these men. Analysis by exposure score also shows no evidence of any hazard. It does show, however, that most of theser men had no exposure to carbon disulphide and those that were exposed only have very short exposures 0 Ninety per cent of these men had left the industry for the last time before 1955, at which point the average age of the group was only 41 . Thus they are a groupw of men who have had at most short exposures at $\mathbb{2}$ young age. It is generally agreed that the risk of IHDO varies according to the total burden of risk factorsD present. Perhaps exposure to higher levels of carbon ${ }^{+}$ disulphide only triggers an ischaemic event in a man who is already at high risk of the disease.

The hypothesis of a reversible direct effect of car $\stackrel{\mathbb{D}}{\mathbb{D}}$ bon disulphide is supported by Nurminen and Hern $\mathbb{\mathbb { D }}$ 
berg. ${ }^{11}$ The mortality of a cohort of 343 Finnish rayon workers exposed to carbon disulphide for at least five years was monitored from 1967 to 1982 . In 1972 a preventive programme was introduced which included removing from exposure all workers with coronary risk factors, and reducing exposure levels below $10 \mathrm{ppm}$. Before the intervention mortality from ischaemic and other heart diseases showed a $4 \cdot 7$-fold excess compared with a control cohort of paper mill workers. After the intervention the mortality rates were similar in the two groups. They concluded that the "cardiotoxic effect of $\mathrm{CS}_{2}$ is reversible."

Tiller et al expressed the hope that further work might throw light on mechanisms concerned in coronary heart disease. ${ }^{3}$ This hope has not been borne out. Tolonen et al found higher blood pressures among their cohort exposed to $\mathrm{CS}_{2}$ than among the comparison group of paper mill workers. ${ }^{4}$ There were, however, no differences in lipids, glucose tolerance, or exercise ECG. Tolonen et al also found a slightly higher prevalence of angina among their Finish workers exposed to $\mathrm{CS}_{2}$ than among their paper mill controls. There were, however, no differences in the prevalence of ischaemic changes on either resting or exercise ECG. Two groups of Japanese workers, one exposed to $\mathrm{CS}_{2}$ and the other not, showed no difference in blood pressure or in the prevalence of angina or ischaemic changes on ECG. Oliver and Weber were unable to find any association between exposure to $\mathrm{CS}_{2}$ and blood pressure. ${ }^{13}$ Few morbidity studies have been done and they provide little convincing evidence either that IHD is more prevalent among workers exposed to $\mathrm{CS}_{2}$ or that levels of coronary risk factors are higher. These negative findings are consistent with the hypothesis that $\mathrm{CS}_{2}$ may act to trigger a clinical event in a man who is at high risk. Perhaps morbidity studies should instead be looking at the effect of $\mathrm{CS}_{2}$ on factors that are related to thrombosis, on the autonomic innervation of the cardiovascular system, and on cardiac muscle and enzymes.

\section{References}

1 Vigliani EC. Carbon disulphide poisoning in viscose rayon factories. Br J Ind Med 1954;11:235-44.

2 Wronska-Nofer T, Szendzikowski S, Obrebska-Parke $\mathbf{M}$. Influence of chronic carbon disulphide intoxication on the development of experimental atherosclerosis in rats. $\mathrm{Br} J$ Ind $\mathrm{Med}$ 1980;37:387-93.

3 Tiller JR, Schilling RSF, Morris JN. Occupational toxic factor in mortality from coronary heart disease. $\mathrm{Br}$ Med $J$ 1968;iv:407-11.

4 Tolonen M, Nurminen M, Hernberg S. Ten-year coronary mortality of workers exposed to carbon disulfide. Scand $J$ Work Environ Health 1979;5:109-14.

5 Nurminen M, Mutonen P, Tolonen M, et al. Quantitated effects of carbon disulphide exposure, elevated blood pressure and ageing on coronary mortality. Am $J$ Epidemiol 1982;115:107-18.

6 Hill ID. Computing man years at risk. Br J Prev Soc Med 1972;26:132-4.

7 Liddell FDK. Simple exact analysis of the standardised mortality ratio. J Epidemiol Community Health 1984;38:85-8.

8 Acheson ED, Barnes HR, Gardner MJ, et al. Formaldehyde process workers and lung cancer. Lancet 1984;i:1066-7.

9 Mancuso TF, Locke BZ. Carbon disulphide as a cause of suicide. J Occup Med 1972;14:595-606.

10 Fox AJ, Collier PF. Low mortality rates in industrial cohort studies due to selection for work and survival in the industry. $\mathrm{Br} J$ Prev Soc Med 1976;30:225-30.

11 Nurminen M, Hernberg S. Effects of intervention on the cardiovascular mortality of workers exposed to carbon disulphide: a 15 year follow up. Br J Ind Med 1985;42:32-5.

12 Tolonen M, Hernberg S, Nordman C-H, et al. Angina pectoris, electrocardiographic findings and blood pressure in Finnish and Japanese workers exposed to carbon disulfide. Int Arch Occup Environ Health 1976;37:249-64.

13 Oliver LC, Weber RP. Chest pain in rubber chemical workers exposed to carbon disulphide and methaemoglobin formers. $\mathrm{Br}$ $J$ Ind Med 1984;41:296-304. 